\title{
The Growing Importance of Sustainable Wildlife Tourism in India and Involving Indian Youth in Promoting Wildlife Conservation
}

\author{
Dr.Shripad Joshi ${ }^{1}$, Mrs. Swati Takkar Dongre ${ }^{2}$ \\ ${ }^{1}$ Principal, Ghanshyam Das Saraf College, Malad, Mumbai, Ph.D. Guide University of Mumbai \\ ${ }^{2}$ Course Co-ordinator, Department of Management Studies, Patkar-Varde Autonomous College, Goregaon, Mumbai, \\ Research Scholar JJTU University, Rajasthan
}

\begin{abstract}
Sustaining and preserving the natural environment is essential for the future generations. India is one of the numerous countries where wildlife or nature-based tourism is growing. Young people must contribute more to wildlife conservation. Those who engage in nature-based tourism may experience wildlife parks, hikes, camping, watches birds, and scuba diving, as well as other experiences, dependent on the natural environment. In addition to providing funds for park management and employment, these types of tourism are considered beneficial to conservation and local economies. Sustainable development has been a fundamental component of youth groups' programmes all around the world. Thus we hear about new youth-led initiatives almost every day, ranging from deforestation, disaster management, and helping animals. While everyone in society is responsible for protecting the community's environmental integrity, young people have a specific interest in undertaking because they will be the ones to use it in the near future. Human existence will be improved by the environmentally friendly utilisation of natural resources and environmentally sustainable economic growth. Millennials know that this is not the right time to sit back and wait for things to happen of their own accord.
\end{abstract}

Keywords: Sustainable Wildlife Tourism, Indian Youth, Wildlife Conservation, Local Communities

\section{INTRODUCTION:}

What is Wild Life Tourism?

Wildlife Tourism is the observation of wildlife in its natural surroundings. It is a great way to be as close to nature amidst the beautiful flora and fauna. Wild life Tourism is an significant part of tourism industry in most of the countries of the world including India. Internationally, it has witnessed a vivid and rapid growth in recent years and is closely aligned with Eco-tourism and sustainable tourism. Additionally, wildlife tourism is a multimillion-dollar industry that offers tourists customized tours and safaris. Getting close to wildlife through non-consumptive means, such as photographing or observing animals in their natural habitats, is considered wildlife tourism. As a recreational activity, it incorporates elements of adventure travel, but also supports the interests of eco-tourism and nature conservation.

Status of Wild Life Tourism in India:

India has an unprecedented growth in Wild Life Tourism and is also gaining importance at global level. India is one of the prevalent wildlife destinations in the world. The country has the greatest wildlife and bird sanctuaries and tiger reserves. Visitors from around the world are drawn to the country for its exotic animals, including Asian Elephants, Asiatic Lions, Bengal Tigers, Sloth Bears, Indian Rhinos and Leopards as well as hundreds of bird species

Tourism in India:

The Travel and tourism industry in India has contributed significantly to its GDP. The sector also creates substantial employment opportunities.

As per the reports published by Ministry of Tourism, Govt. of India in the Annual Report of 2020-21, this is the contribution of the travel and tourism sector to India's GDP. 
International Advanced Research Journal in Science, Engineering and Technology

Vol. 8, Issue 12, December 2021

DOI: $10.17148 /$ IARJSET.2021.81222

\begin{tabular}{|l|l|l|l|l|l|l|}
\hline & $2013-14$ & $2014-15$ & $2015-16$ & $2016-17$ & $2017-18$ & $2018-19$ \\
\hline Share in GDP (in \%): & 5.68 & 5.81 & 5.09 & 5.04 & 5.00 & 5.00 \\
\hline Direct (in \%) & 3.06 & 3.14 & 2.65 & 2.62 & 2.6 & 2.6 \\
\hline Indirect (in \%) & 2.62 & 2.67 & 2.44 & 2.42 & 2.4 & 2.4 \\
\hline Share in Jobs(in \%) & 11.91 & 12.14 & 12.38 & 12.2 & 12.29 & 12.95 \\
\hline Direct (\%) & 5.19 & 5.3 & 5.4 & 5.32 & 5.36 & 5.65 \\
\hline Indirect (\%) & 6.72 & 6.84 & 6.98 & 6.88 & 6.93 & 7.3 \\
\hline $\begin{array}{l}\text { Direct + Indirect jobs } \\
\text { due to tourism } \\
\text { (in million) }\end{array}$ & 67.19 & 69.56 & 72.26 & 75.71 & 80.54 & 88.72 \\
\hline
\end{tabular}

Note: The above estimates have been updated using NAS 2020

\begin{abstract}
${ }^{\text {i }}$ Statistics derived National Accounts Statistics[NAS] 2020
Although the Coronavirus has slowed down the travel and tourism industry in India, the spirit of those involved has not yet been broken. A number of experts have noted the importance of focusing on the potential of domestic tourism and trying to gain some profit from it.

One of such prominent area is Wild life Tourism in India.
\end{abstract}

\title{
Impacts of Wildlife Tourism:
}

- Wilderness areas in India are divided into 75 National Parks and 421 Sanctuaries. Nineteen of these are overseen by Project Tiger. Ranthambore, Bandhavgarh and Kanha National Parks are some of the most popular "Project Tiger" wildlife reserves.

- The wildlife plays an essential part in upholding a balanced ecosystem. There are many animals which are great predators and that is the primary reason for ecological development.

- The wildlife is also regarded as one of the most important factors contributing to the development of world trade and national income.

- Wildlife is a natural source of raw materials we can use to start any business, factory, or enterprise.

- Several national parks in India are experiencing wildlife tourism at unsustainable levels and are posing multiple problems as a result. Wildlife tourism has the potential to cause significant turbulences to animals in their natural habitats.

- Despite its seemingly innocent nature, the practice of selling slots for tourists to take part in sanctioned hunts can negatively influence populations through indirect means.

There is no escaping the fact that as tourism grows and expands, we will see increased pressure on the environment and wildlife.

\section{Contribution of Youth and Government Initiatives:}

India has a got a larger population of Young people and somewhere it came to my thoughts that we should channelize this youth in right direction and use their energy potential in saving the environment.

In many Indian parks, wildlife tourism has become unsustainable and is causing a variety of problems. The funding for protecting wildlife needs to be increased.

"In some parks, the land is being grabbed by wealthy outsiders who are buying property from local residents at incredibly high prices," says Karanth. ${ }^{\text {ii }}$

According to Karanth, if local communities lack the resources or skills needed to set up their own facilities, tensions will escalate around these parks.

Indeed, India is rich in wildlife. India's parks are crucial to conserving these species.

Currently, unregulated tourism creates a huge amount of pressure on parks and park managers already facing a number of challenges".

From the dawn of 1930s, India has been working on wildlife conservation. It began with formation of famous Jim Corbett National Park. Indian Government has started viable ventures for natural life preservation to check human infringement.

One of the most creditable initiatives is the Wildlife Protection Act of 1972, which forbids the trade in rare and species on the verge of extinction.

Here are some of the important conservation initiatives that Indian Government has undertaken regarding Wildlife Protection and Conservation: 


\title{
International Advanced Research Journal in Science, Engineering and Technology
}

\author{
Vol. 8, Issue 12, December 2021
}

\section{DOI: 10.17148/IARJSET.2021.81222}

- As per the Wildlife Protection Act of 1972, Government of India (GOI) made Secured Regions like National Parks, Sanctuaries, Conservancy and Community Shelters for the natural life and forced restraints on those involved in unlawful act of hunting.

- The Central Government began the Coordinates Advancement of Natural Life Living Space Plot for replacing the imperiled species, but later changed it by adding the unused component, Restoration of Imperiled Species which included creatures like "Hangul/Stag Deer in Jammu \& Kashmir, Vultures in Punjab, Haryana and Gujarat, Snow Panther in Jammu \& Kashmir, Himachal Pradesh, Uttarakhand and Arunachal Pradesh, Swiftlet in Andaman \& Nicobar Islands, Nilgiri Tahr in Tamil Nadu, Sangai Deer in Manipur".

- Anti-poaching exercises have been escalated by the GOI, and the government has instituted an uncommon monitoring technique. A National Tiger Preservation Specialist was established by the Government of India in order to improve tiger preservation.

- In Karnataka, Maharashtra and Odisha, the Special Tiger Protection Force (STPF) is also deployed. Assam's Kaziranga National Park and the borders of Madhya Pradesh's Ratapani Wildlife Sanctuary are being monitored using electronic surveillance systems..

It is the responsibility of the youth to protect nature. Wildlife preservation is exceptionally critical, in arrange to protect creature species for future eras. The vitality and imaginative thoughts of youth can lead to positive changes in nature preservation. In reality, numerous youthful individuals have been included in exercises to assist natural life preservation, by volunteering their services to Wildlife conservation organizations, as well as in government and UN activities.

India has been domestic to a few unimaginable natural life warriors like Valmik Thapar, Romulus Whitaker, Uma Ramakrishnan, Prerna Singh Bindra, Latika Nath, Bittu Sahgal and K. Ullas Karanth, to title a couple, of who have went through their lives working, composing and battling for preservation and raising mindfulness approximately India's animal kingdom. ${ }^{\text {iii }}$

\section{Contribution of World Wild Life Fund and other NGO's working in Wildlife Conservation:}

- The World Wildlife Fund popularly known as WWF was founded in April, 1961, and established itself in Morges, Switzerland, at IUCN's headquarters. The giant panda becomes the logo for WWF.

- Throughout its 60-year existence, WWF has been working to ensure the survival of people and nature. As the world's leading conservation organization, WWF is active in nearly 100 countries.

- The World Wide Fund for Nature-India was founded with the express purpose of conserving the country's wildlife and natural habitats. Founded on 27 November 1969, it became a Charitable Public Trust.

- The focus of WWF India was heavily on wildlife conservation and nature preservation during the 1970 s and 1980s.

- In addition to their conservation initiatives for the tiger and other priority species, they also focus on environmental education, sustainable agriculture, marine conservation, engaging businesses to adopt better environmental practices, and inspiring citizens to take positive action for the planet.

iv Different NGO's in India who have also helped in the conservation and preservation of wildlife in India are:

- TRAFFIC India fights wildlife trafficking in India

- The Wildlife Trust of India has been extremely vocal about Red Jungle fowls and Golden Haired Langurs.

- Wildlife First promotes the conservation of wildlife in Karnataka

- The Wildlife Protection Society of India (WPSI) monitors illegal wildlife trade with state governments

- Greenpeace

\section{Objectives:}

1. To understand the evolution and responsiveness of Wildlife Tourism within India.

2. To analyze the impacts of Wildlife Tourism in India.

3. To study the disturbances caused to Wildlife due to Tourist activities in the areas like Wildlife Sanctuaries, National Parks, Tiger Reserves, Bird Sanctuaries.

4. To analyze the dependency of a healthy ecosystem on the wildlife diversity.

5. To study the Environmentally-friendly, culturally-sensitive tourism that emphasizes economic development of local communities in a great way to promote sustainable development.

6. To understand the technique for protecting natural habitats of organisms through Wildlife conservation.

7. To harness the innovation and energy of Indian Youth and combine it with the wisdom that comes from experience, if we are expecting to make the change we need in Sustainable Wildlife Tourism and Wildlife Conservation.

8. To raise an awareness among the school children about Wildlife conservation and Sustainable Development.

9. To volunteer for raising an alertness about the importance of wildlife and wilderness amongst tourists.

10. To raise an awareness towards a more responsible tourist behavior and channelizing the energy potential of Indian Youth to waste reduction behavior. 


\section{Hypothesis:}

Null Hypothesis (H0): The role of Indian Youth still remains unmapped as far as Wildlife Conservation is concerned in India.

Alternative Hypothesis (H1): The role of Indian Youth is extremely contributing towards Wildlife Conservation in India.

\section{RESEARCH METHODOLOGY:}

The research methodology taken in this research paper covers both Primary and Secondary data.

Primary Data:

A sample data of 99 respondents who are the young students, was taken for the study. A questionnaire in the form of Google forms was given to the respondents and their view points were sought.

Secondary Data:

The secondary sources of information include E-resources like World Wildlife Websites, Google Search Engine, and Research Papers on Wild life Tourism, Blogs on Wildlife Tourism and Wildlife Conservation

\section{FINDINGS AND ANALYSIS:}

\section{Age Group:}

The questionnaire was filled by 99 respondents between the age group of 15 to 25 years

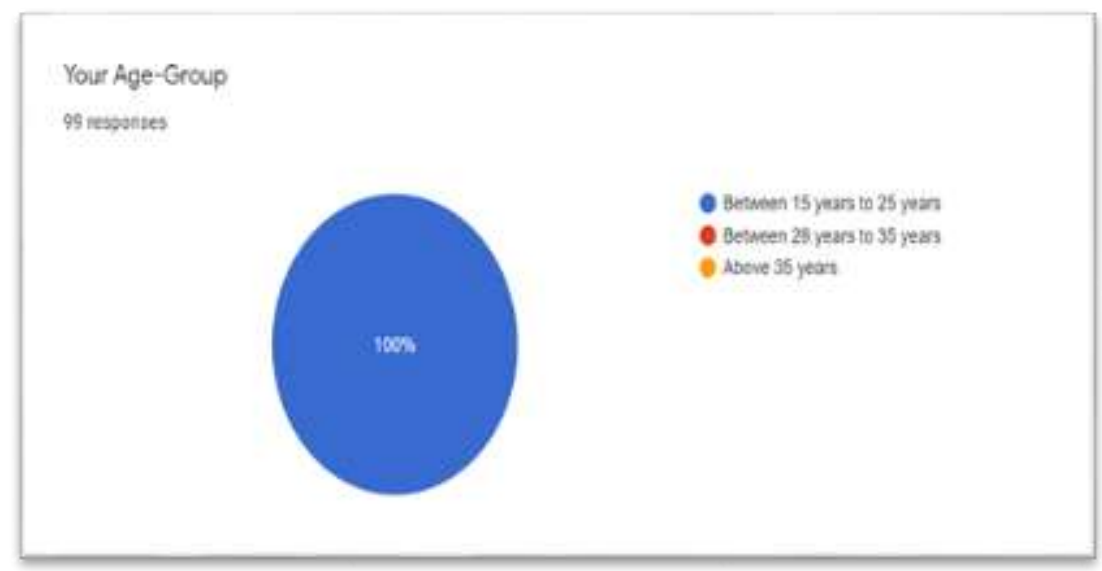

\section{Gender:}

Out of 99 repondents , $59 \%$ were Females and $40 \%$ were Males

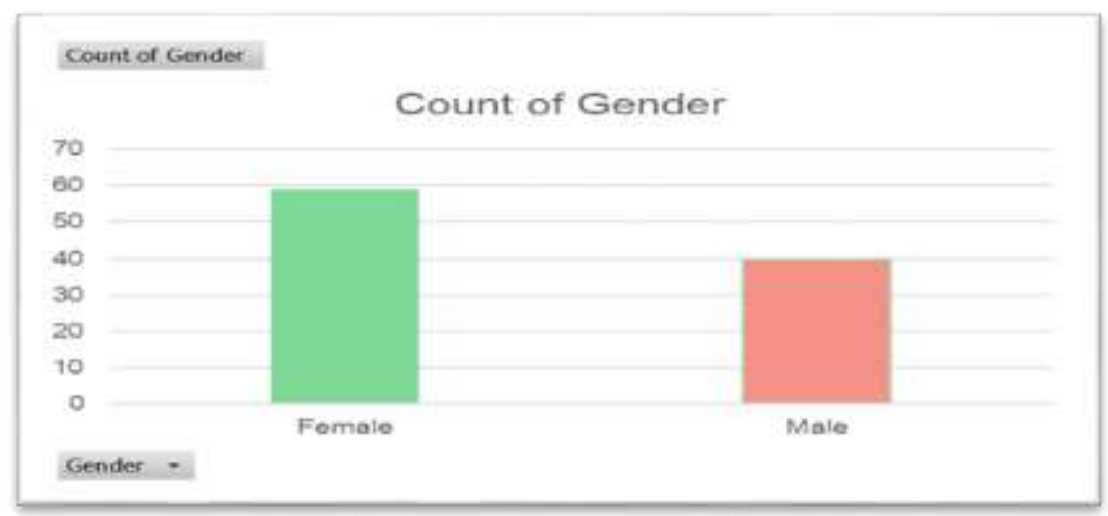

Are you aware about Wildlife Tourism?

As per the responses received $68 \%$ of the people were aware about Wildlife Tourism. 
Vol. 8, Issue 12, December 2021

DOI: $10.17148 /$ IARJSET.2021.81222

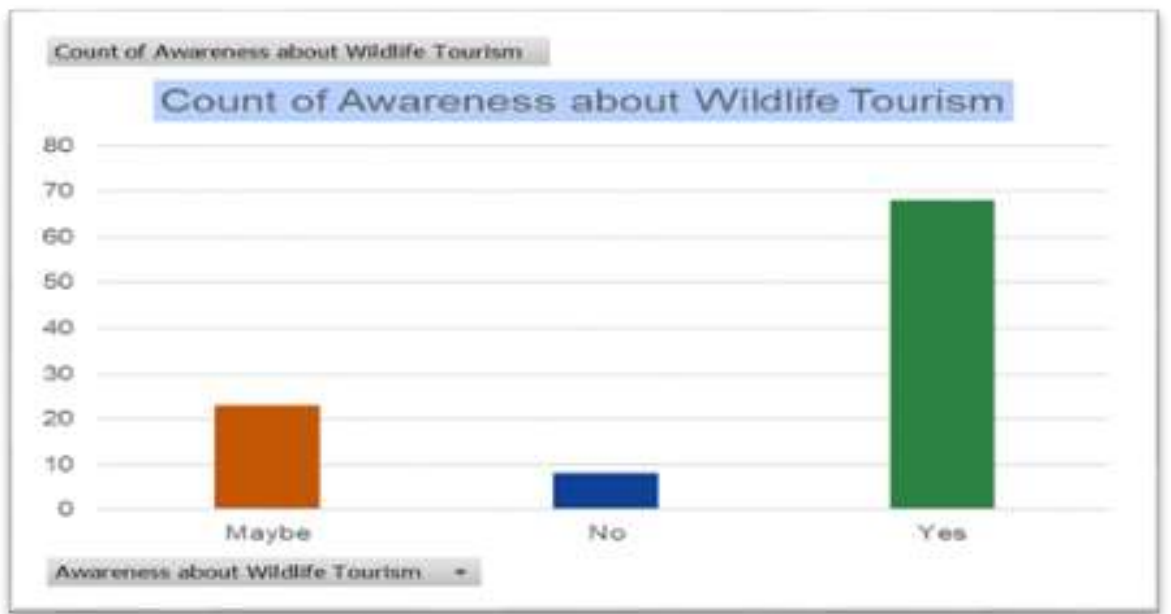

Have you visited any Wildlife Sanctuaries, Bird Sanctuaries, Tiger Reserves or any Jungle Safari?

Out of the 99 respondents, $60 \%$ people have taken the experience of Jungle Safari, Wildlife Sanctuaries, and National Parks etc.

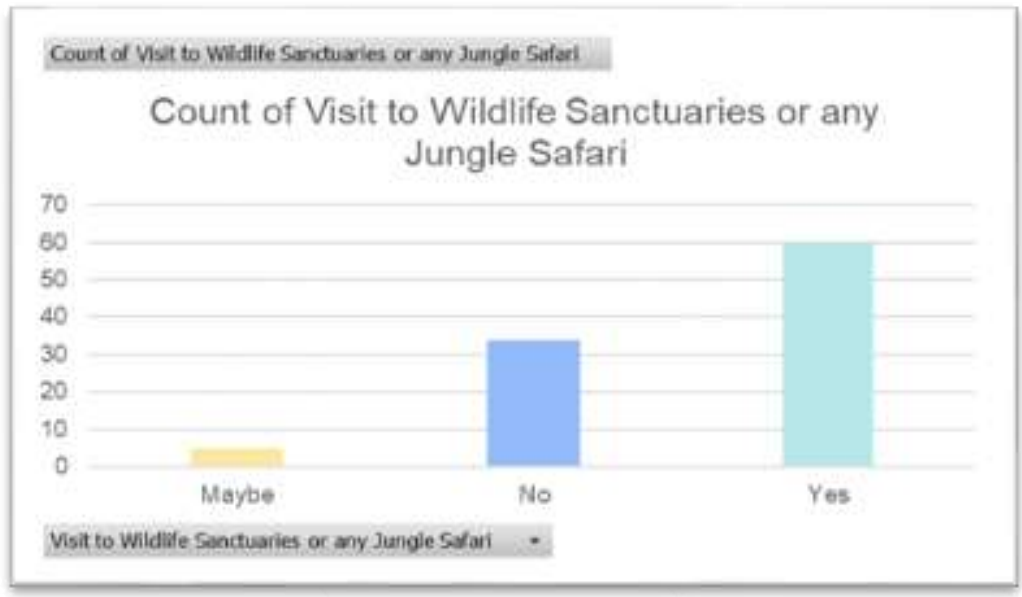

Do you find that the travel to such places is worth?

Almost $85 \%$ of the youth has agreed, that visit to wildlife sanctuaries, bird sanctuaries is worthy.

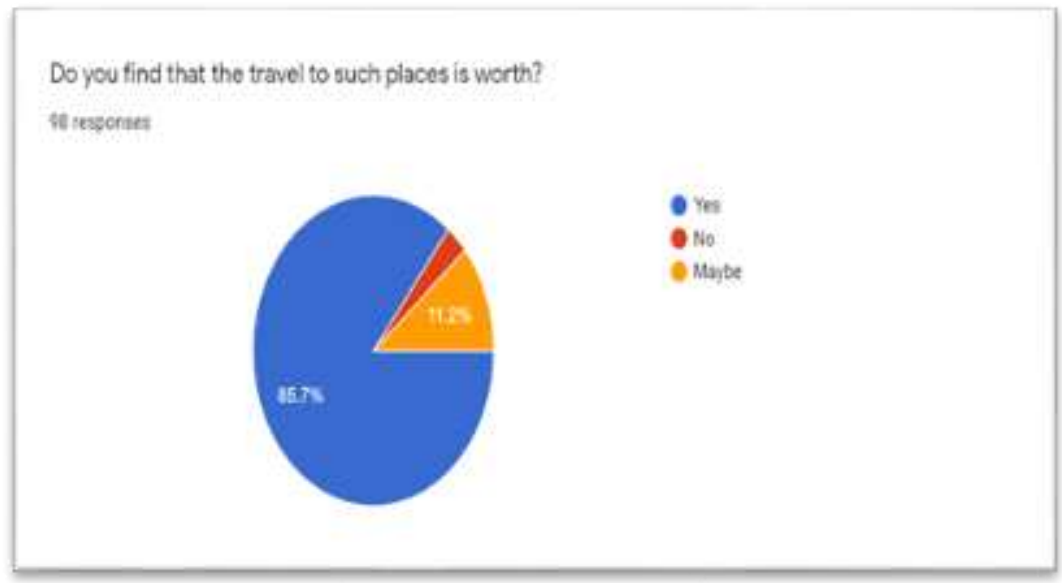

Does Wildlife help in maintaining Ecological balance on earth?

About $90 \%$ of the respondents have agreed that Widllife helps in maintaining the Ecological balance on Earth. 
DOI: 10.17148/IARJSET.2021.81222

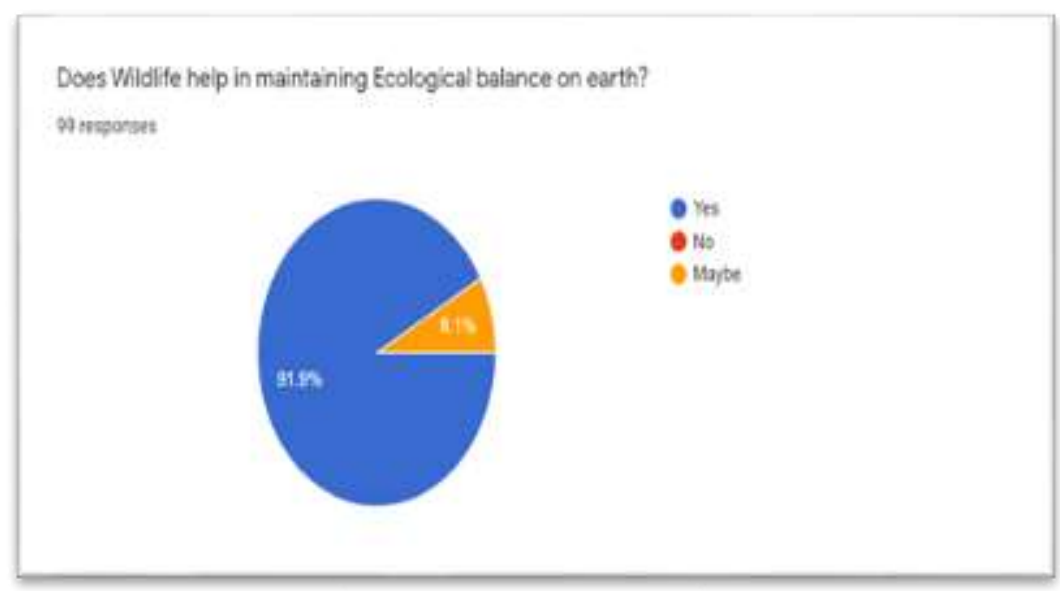

Are you aware about govt. initiatives towards wildlife conservation? If yes ? Which one?

As per the responses, about $48 \%$ were aware about Wildlife protection act, $43 \%$ were aware about Project Tiger. Only 4\% were aware about Government of India's initiative about Project Rhino, 3\% aware about Project Elephant. Hardly 1 $\%$ of the youth was aware about Project Turtle.

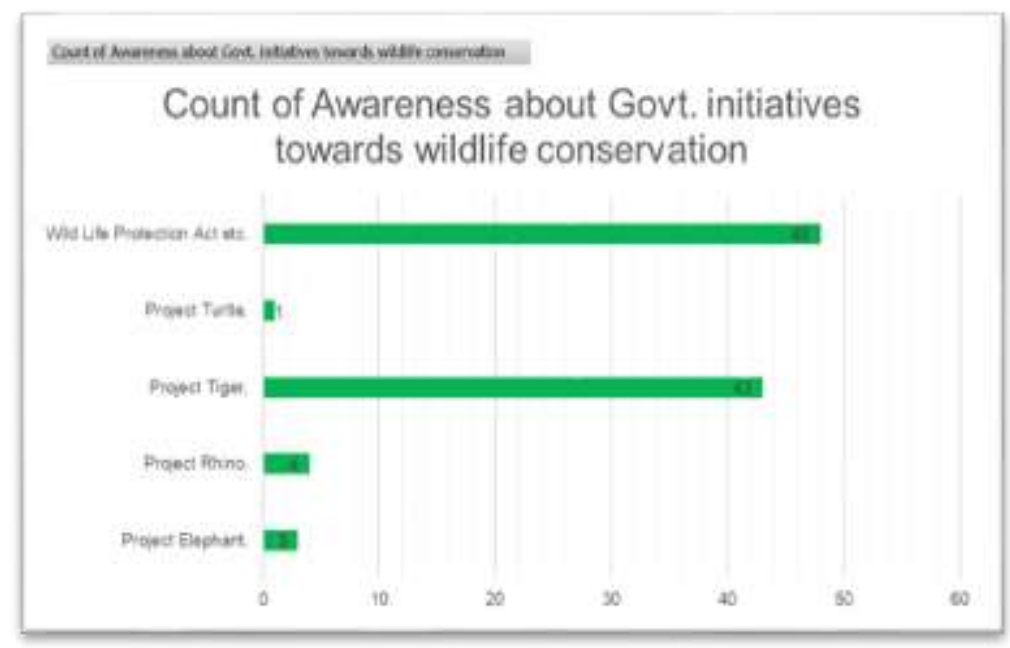

Do you agree that the steps taken by Indian government suffice the wildlife conservation?

As per the data received, almost $50 \%$ of the respondents were not sure about the initiatives taken by Government of India towards wildlife conservation were sufficient. Only approx. 37\% respondents were affirmative in answering.

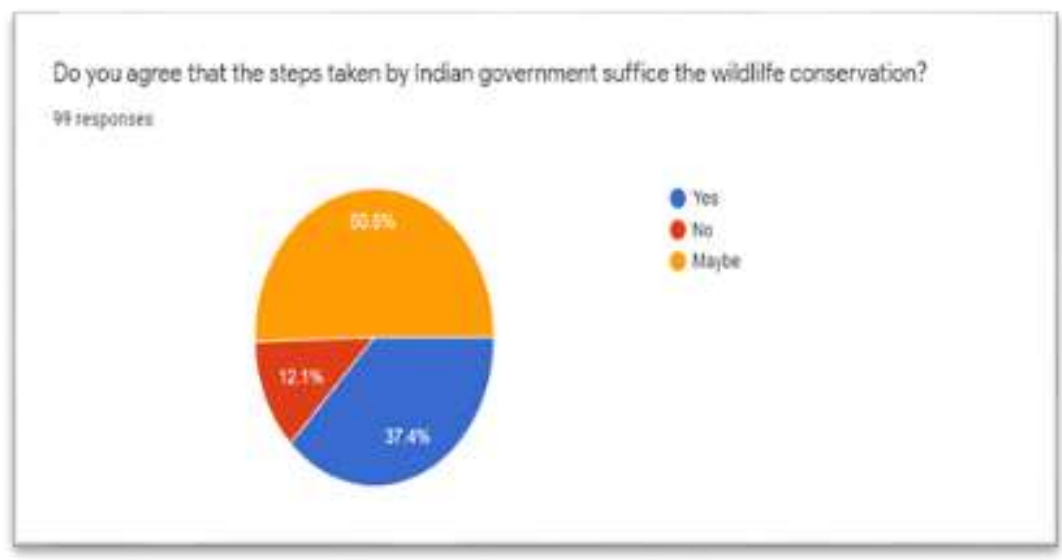

Are you aware about the threats Wildlife is facing as far as India is concerned?

Out of the 99 respondents, almost 66\% were aware about Deforestation due to Fires in Jungles, Agriculture Activities, Land Development etc., 19\% were aware about Hunting of Wild Animals, 13\% were aware about Poaching. However 
only $1 \%$ of the population was aware about Raiding. This itself shows that the more awareness should be created amongst Youth about Wildlife Conservation and Sustainable development.

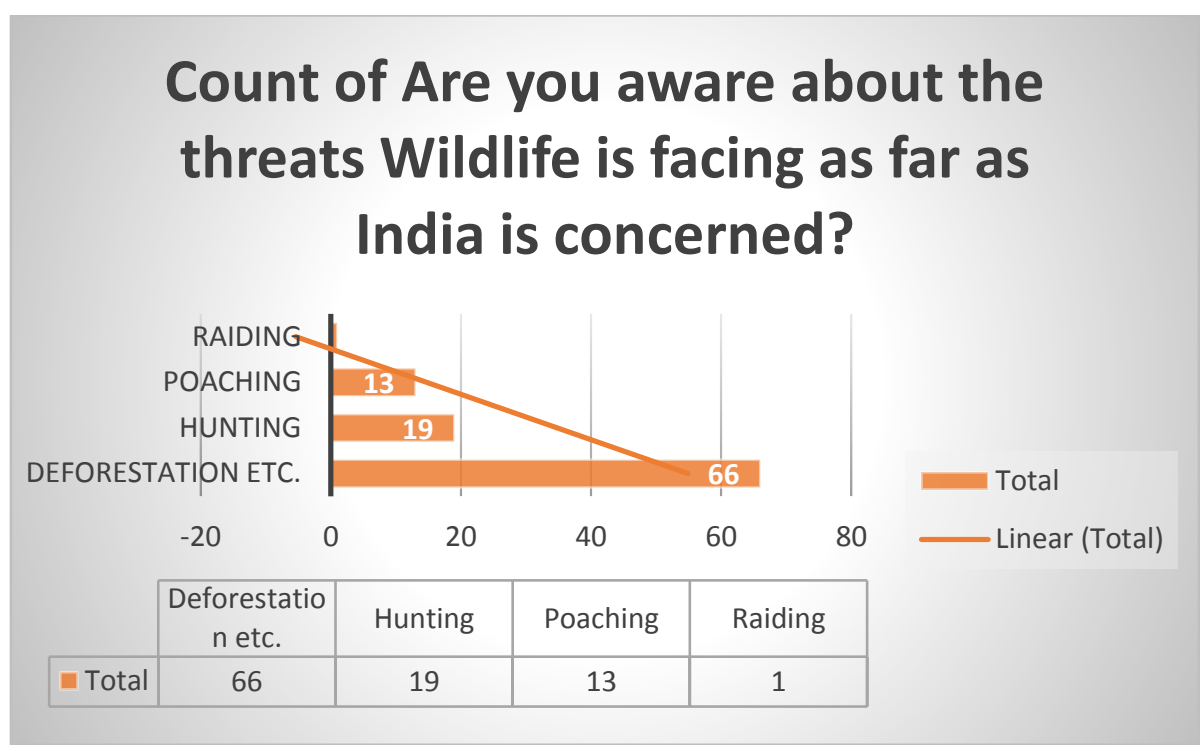

How do you think the Indian Youth can be used for promoting towards Wildlife Conservation? A summarized view point of this question is given below as per what the respondents said. These are some ways young people can protect the environment and ecosystems and take control of their future:

- Get Involved With Environmental Organizations or Launch Your Own Initiative

- Decrease use of Paper or Recycle Paper. Reduce, Reuse and Recycle resources to protect Wildlife habitat.

- Do not throw plastic, paper, and metal waste in the trash, but separate them and place them in a recycling bin

- Take shorter baths and turn off your taps when not in use to save water.

- In a similar manner, it's important to be mindful of your electricity consumption, and to adapt your behavior in order to reduce the demand for energy production and thereby preserve fossil fuel resources

- Plastic is one of the main component for aggravating soil and marine pollution, put in danger the land and marine life. So, Youth should create mindfulness towards waste reduction behavior and use Eco-friendly products.

- Only purchase what is needed, unnecessary consumption can bring stress on our natural resources as they are limited in number. Youth should become a responsible consumer.

- Social media can be widely used for spreading awareness about Wildlife Conservation as youth is prominently active on Social media.

- Conducting Seminars, Planning Visits to Wildlife Reserves, Participating in Government initiatives.

- Do not participate in Sport Hunting

- Creating an awareness about not cutting trees via banners or videos, arranging talk shows to educate people, plant more trees.

- Joining NGO's regarding Wildlife Initiatives.

- Arranging Educational trips at school and college level to National Parks, Sanctuaries etc. to sensitize students towards Wildlife and its importance.

Do you believe that awareness created at school or college level can change the mindset of the youth in promoting efforts towards wildlife conservation? If Yes! How? if No! state why you feel so?

We received a positive response from the respondents for this question. Most of them have suggested that awareness should be created at school level because if the value of conservation is inculcated in youth as they are today's generation it would create major impact on society and they would look forward to protect wildlife and educate people about it and make them more responsible.

\section{REVIEW OF LITERATURE:}

- The research paper published by Heesup Han, Jongsik Yu \& Wansoo Kim (2018) on "Youth travelers and waste reduction behaviors while traveling to tourist destinations", in the Journal of Travel \& Tourism Marketing, draws attention towards the increased aspect of Youth Tourists all over the world. It implies the Theory of Planned behavior for analyzing the waste reduction behavior of Youth Tourists. The study is identifying the vital variables in environmental 


\section{International Advanced Research Journal in Science, Engineering and Technology}

\section{Vol. 8, Issue 12, December 2021}

\section{DOI: $10.17148 /$ IARJSET.2021.81222}

behavior that is green image, environmental awareness and anticipated feelings. One of the limitation of their study is that the research sample is restricted to Korean students.

- According to the research paper published by Aruna Rao, Shalini Saksena (2021) : Wild tourism and local communities: Evidence from India, in the Journal of Annals of Tourism Research Empirical Insights, Elsevier, Wildlife tourism has a significant impact on the livelihoods of locals around Ranthambhore National Park in India, which is known for its Tiger reserve. The study also investigates the local resident's awareness regarding economic, sociocultural, ecological impacts of tourism. The research indicates that the mass community perceptions are mixed on the source of revenue, impacts of tourism expansion.

- The research paper published by Karanth, K., DeFries, R., Srivathsa, A., \& Sankaraman, V. (2012). Wildlife tourists in India's emerging economy: Potential for a conservation constituency, studies three National Parks and Tiger Reserves in India, Ranthambore, Kanha, Nagarhole which are one of the most prominent wildlife sanctuaries of India where there is a major inflow of tourists. The research indicates that the growing wildlife tourism is a challenge for wildlife conservation in India and hence there is a need for raising an awareness and educating the people who control these sites and also educating the tourists and making them responsible tourists.

- According to the research paper published by Puri, Mahi \& Srivathsa, Arjun \& Karanth, Krithi \& Kumar, Narayanarao \& Karanth, K. (2015). Multiscale distribution models for conserving widespread species: The case of sloth bear Melursus ursinus in India, emphasizes the need to incorporate human-reformed areas with existing conservation sites. The learning states patterns of sloth bear distribution in India are determined by the existence of deciduous forests, scrubland and sterile land areas. Even though the existence and scope of protected areas emerged as a constructive driver of sloth bear distribution, wild cover had the maximum affirmative influence.

- As per the research paper published by Salazar, Gabby \& Ramakrishna, Ishika \& Satheesh, Nitya \& Mills, Morena \& Monroe, Martha \& Karanth, Krithi. (2021) on The challenge of measuring children's attitudes toward wildlife in rural India in the International Research in Geographical and Environmental Education, The approach of people influence the nature of their interfaces with wildlife and sustenance for conservation. There are many environmental education programs which seek to impact children's outlooks concerning wildlife and the environment. The study used different tools for analyzing the children's attitudes and they found that many times children were hesitant to reply, or they had fear in the mind about wild animals and they were less familiar and tried to copy their peers. So the research concludes saying that there should be properly developed tools to analyze the attitude of children towards wildlife.

\section{CONCLUSION:}

- The increasing extinction of animals, which would have a negative impact on the environment, has created an alarming situation around the world.

- Wildlife conservation is the need of the hour, and it involves studying and protecting animals and their habitats.

- Students that are interested about animals might follow this job and help to save wildlife. This career is ideal for those who are passionate about animals and want to learn more about them as well as preserve them.

- Government agencies, NGOs, academia, wildlife photography, writing magazines, and other organizations all offer job options in the field of wildlife conservation.

- Students studying wildlife conservation learn about biodiversity surveys and research, conservation plans, history, and environmental law, among other things. As per the findings, it is necessary to explore more in the area of wildlife conservation.

- There is a large number of Indian Youth who is unaware about the wildlife conservation and sustainable development. So, if we could take steps in sensitizing them about the threats which pose to the wildlife and utilize their energy potential for initiating a change in protection of the flora and fauna, it would prove beneficial to the Society.

- Wildlife tourism is becoming a popular niche tourism activity in India, with most visitors coming from within the country. Despite popular belief, wildlife tourism can actually assist jungle residents if it is done with care. Poachers are deterred by the presence of tourists in these locations, since they prefer to carry out their criminal actions in complete obscurity.

- India can also institutionalize tourism for conservation by ensuring that a significant amount of tourism profits is spent on poaching control, among other things.

- The research concludes that though we have done so much in the area of Wildlife Conservation, yet it is not sufficient. We need to take more steps for sensitizing our Young people and making them work towards inculcating a eco-friendly behavior and conserve our wildlife resources, so that they are also available for the future generations to come. 


\title{
International Advanced Research Journal in Science, Engineering and Technology
}

\author{
Vol. 8, Issue 12, December 2021
}

DOI: $10.17148 /$ IARJSET.2021.81222

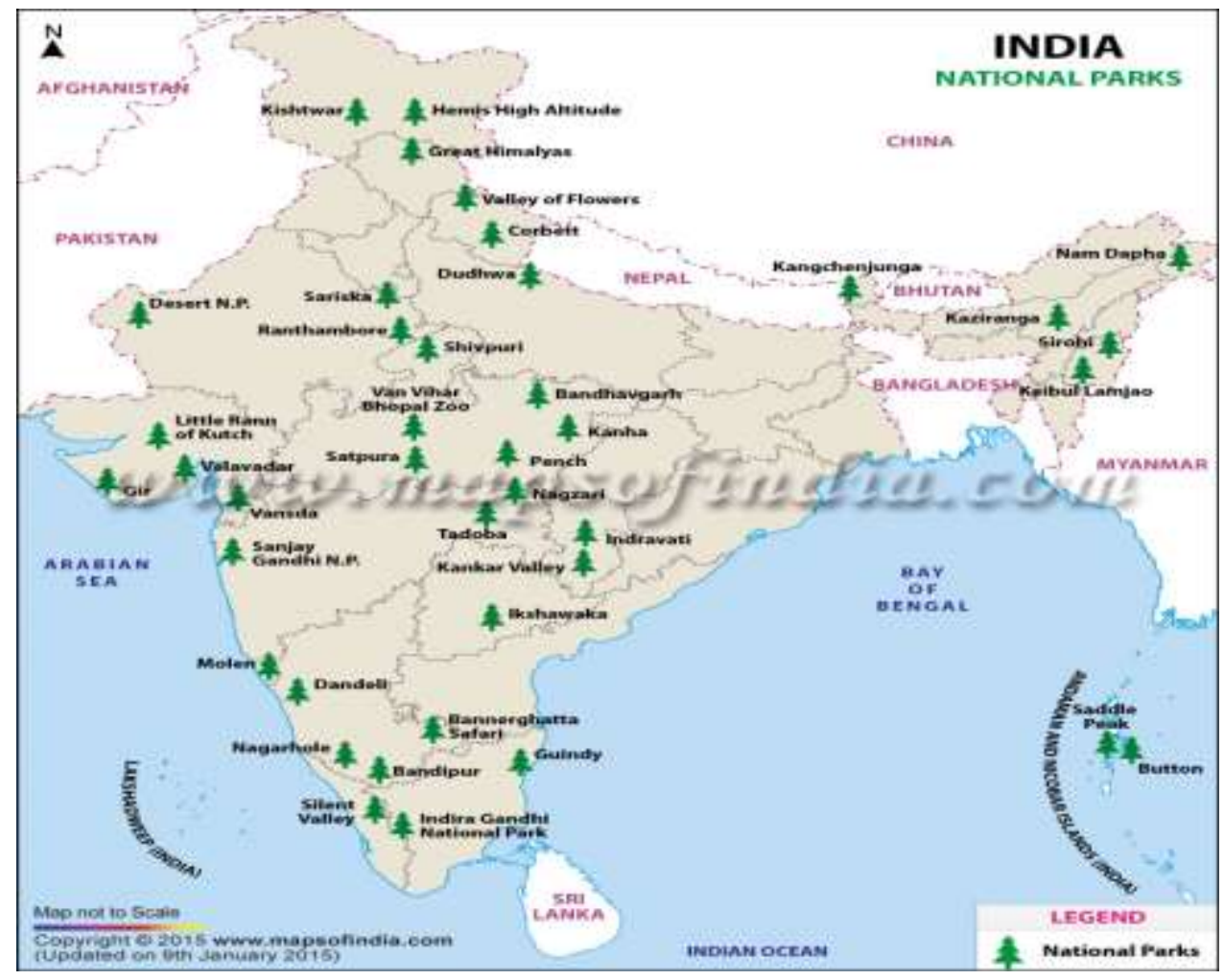

${ }^{\mathrm{i}}$ https://tourism.gov.in/annual-reports/annual-report-2020-21

${ }^{\text {ii }}$ Centre for Wildlife Studies (www.cwsindia.org) Dr. Krithi K Karanth is Chief Conservation Scientist and Executive Director at CWS and Adjunct Faculty at Duke and NCBS.

iii https://homegrown.co.in/article/802684/young-indians-championing-wildlife-conservation-in-india

${ }^{\text {iv }}$ https://www.indianholiday.com/wildlife-india/wildlife-conservation-in-india/ngos-in-india.html

\section{REFERENCES:}

- Heesup Han, Jongsik Yu \& Wansoo Kim (2018): Youth travelers and waste reduction behaviors while traveling to tourist destinations, Journal of Travel \& Tourism Marketing, DOI: 10.1080/10548408.2018.1435335

- Aruna Rao, Shalini Saksena (2021) : Wild tourism and local communities: Evidence from India, Journal of Annals of Tourism Research Empirical Insights, Elsevier

- Moorhouse TP, Dahlsjö CAL, Baker SE, D'Cruze NC, Macdonald DW (2015) The Customer Isn't Always Right - Conservation and Animal Welfare Implications of the Increasing Demand for Wildlife Tourism. PLoS ONE 10(10): e0138939.

- Curtin, Susanna(2005)'Nature, Wild Animals and Tourism: An Experiential View',Journal of Ecotourism,4:1,1 — 15

- Dr.Bedabrat Saika Scope for Livelihood Intervention Based on Wildlife Tourism in Nameri Natioanl Park of Assam: An Analysis Indian Journal of Applied Research, Vol. 5, Issue: 10, October, 2015

- Karanth, K., DeFries, R., Srivathsa, A., \& Sankaraman, V. (2012). Wildlife tourists in India's emerging economy: Potential for a conservation constituency? Oryx, 46(3), 382-390. doi:10.1017/S003060531100086X

- Puri, Mahi \& Srivathsa, Arjun \& Karanth, Krithi \& Kumar, Narayanarao \& Karanth, K. (2015). Multiscale distribution models for conserving widespread species: The case of sloth bear Melursus ursinus in India. Diversity and Distributions. 21. 10.1111/ddi.12335.

- Karanth, Krithi \& Gopalaswamy, Arjun \& Krishna Prasad, Parvathi \& Dasgupta, Shreya. (2013). Patterns of human-wildlife conflicts and compensation: Insights from Western Ghats protected areas. Biological Conservation. 166. 10.1016/j.biocon.2013.06.027.

- Mariyam, Dincy \& Puri, Mahi \& Harihar, Abishek \& Karanth, Krithi. (2021). Benefits Beyond Borders: Assessing Landowner Willingness-toAccept Incentives for Conservation Outside Protected Areas. Frontiers in Ecology and Evolution. 10.3389/fevo.2021.663043.

- Salazar, Gabby \& Ramakrishna, Ishika \& Satheesh, Nitya \& Mills, Morena \& Monroe, Martha \& Karanth, Krithi. (2021). The challenge of measuring children's attitudes toward wildlife in rural India. International Research in Geographical and Environmental Education. 1-17. 10.1080/10382046.2021.1897339.

- Robbins, Paul \& Tripuraneni, Vaishnavi \& Karanth, Krithi \& Chhatre, Ashwini. (2020). Coffee, Trees, and Labor: Political Economy of Biodiversity in Commodity Agroforests. Annals of the American Association of Geographers. 111. 10.1080/24694452.2020.1803726.

- Lee, S. and Phau, I. (2018), "Young tourists' perceptions of authenticity, perceived value and satisfaction: the case of Little India, Singapore", Young Consumers, Vol. 19 No. 1, pp. 70-86

- Chakrawertti, S. (2005, March 20). The story of vanishing tigers. The Times of India. Retrieved from https://timesofindia.indiatimes.com/india/The-story-of-vanishing-tigers/articleshow/1056949.cms [Google Scholar]

- Kapur, Radhika. (2018). The Significance of Wildlife Tourism. https://www.researchgate.net/publication/328412700_The_Significance_of_Wildlife_Tourism 